\title{
Damage of Wood-Concrete Composite subjected to variable hygrometric conditions
}

\author{
L. Loulou ${ }^{1}$, S. Caré ${ }^{1 a}$, R. Le Roy ${ }^{1}$ and M. Bornert ${ }^{1}$ \\ ${ }^{1}$ Université Paris-Est, UR Navier, Laboratoire Central des Ponts et Chaussées / Ecole des Ponts \\ ParisTech / CNRS, 77420 Champs sur Marne, France
}

\begin{abstract}
This paper discusses the factors influencing the durability of glued assemblies of wood and cementitious material under variable hygrometric conditions. The composite specimens are composed of cement paste connected to plywood using epoxy glue. The cement paste is subjected to autogeneous shrinkage and the wood is subjected to imbibition test. Plywood is used so that the swelling deformations due to the imbibition process are parallel to the connection plane. Swelling strains in wood are related to the water content measured by gammadensimetry technique. Global strains above and below the glue interface have been measured and have been compared to the free strains. We showed that there are restrained deformations at the glue interface and that the cement paste is damaged. Local strains have been characterized by means of the digital image correlation technique. We showed in particular that the deformations in wood are related to the microstructure of the layers of plywood and that the restrained deformations at the glue interface lead to a bending of the cement paste. In the case of strong adhesion properties, this bending induces cracking in cement paste.
\end{abstract}

\section{Introduction}

Within the context of sustainable development, wood-concrete composite structures appear to be an innovative solution because they combine mechanical performance with minimum environmental impact. In this context, the Navier laboratory has developed new bridges structures composed of ultra-high-performance fiber-reinforced concrete (UHPFRC) glued on wood beams. Three-point flexural tests carried out on these wood-concrete beams showed that glued assembly of the two materials is an efficient technique in terms of stiffness and ultimate load of the beams $[1,2]$. Glued assembly is stiffer than the specimen made using common joining techniques (for instance expanded metal band) and the ultimate load is roughly $20 \%$ higher.

These results, however, have to be confirmed when the wood-concrete composite is subjected to variable hygrometric conditions because moisture content variation may induce damage in the different materials (glue, wood and concrete). At first, adhesives are very sensitive to environment conditions. Properties of adhesive joints may be altered by irreversible mechanisms when they are exposed to humidity. In case of structural bonded timber joints [3], it is shown that water may

a e-mail : sabine.care@lcpc.fr

This is an Open Access article distributed under the terms of the Creative Commons Attribution-Noncommercial License 3.0, which permits unrestricted use, distribution, and reproduction in any noncommercial medium, provided the original work is properly cited. 
physically damage the adhesive by hydrolysis or cracking, leading to a loss in the strength of the adherent itself and may produce an unstable adhesive/adherent interface. Secondly the materials wood and concrete may be damaged $[4,5,6]$ due to restrained deformations during drying process. In the case of wood, it is possible to observe drying defects due to shrinkage anisotropy leading to warping and cracking. In the case of concrete, as cement is mixed with more water than what is needed to hydrate it, much of the remaining water evaporates, leading to shrinkage and thus to cracking because of restrained deformations due to aggregates. Finally, possible restrained deformation at the concrete/wood interface may induce stresses in wood or in cementitious materials during the variable hygrometric conditions.

The aim of this paper is to evaluate the potential effect of the restrained deformations on the durability of the wood/concrete assembly. We present here an accelerated degradation test which allows characterizing the restrained deformation at the glue interface.

\section{Materials and methods}

\subsection{Samples and degradation test}

Sample: The composite specimen $(70 \mathrm{~mm} \times 65 \mathrm{~mm} \times 50 \mathrm{~mm})$ is composed of cementitious material connected to wood sample using epoxy glue. The wood sample is made from three glued plywood sheets composed of eleven layers of Okoumé. Okoumé (Aucoumea Klaineana Pierre) is an exotic wood species grown in Africa and is often used to manufacture plywood. The cementitious material is a cement paste with a water to cement ratio $\mathrm{W} / \mathrm{C}$ equal to 0.4 and made of Portland Cement (European grade CEM I, 52.5).

Degradation test: The cement paste is sealed with a vinyl sheet to prevent evaporation and the wood is subjected to a unidirectional imbibition test from below (see fig. 1). Two cases are studied: composite samples with fresh cement paste glued to plywood (case W $+\mathrm{CP}$ ) and with old cement paste (28-days-old) glued to plywood (case W + CP 28 days). In the first case, the imbibition test is carried out one day after the casting and in the second case, one day after the gluing of the cement paste. Thus, the two studied cases allow analysing the effect of the autogenous shrinkage and the stiffness of the cement paste on the damage mechanisms of the composite. Plywood is used so that the swelling deformations due to the imbibition process are parallel to the connection plane. This study does no take into account the effects of the warping of the wood due to its anisotropy.

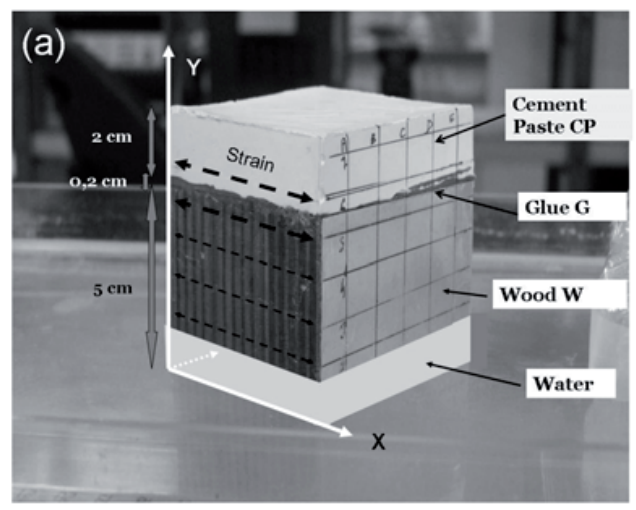

(b)

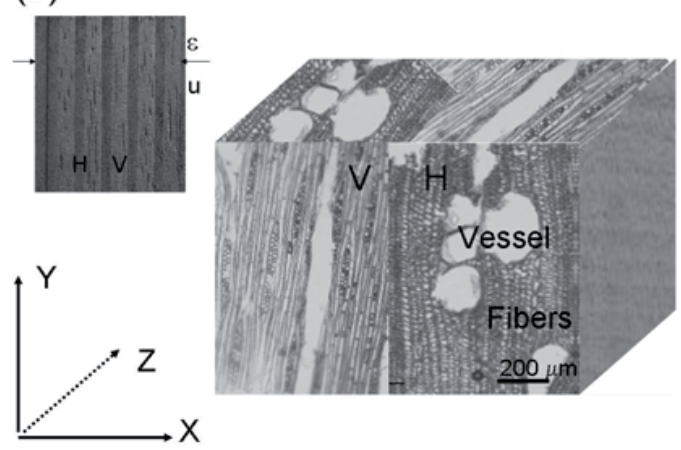

Fig. 1. (a) Composite sample made from cement paste (CP) glued to plywood (W) subjected to an imbibition

test. (b) Microstructure of Okoumé (Aucoumea Klaineana Pierre): observations of two adjacent plies by optical microscopy. V layer: the wood fibres are vertical and H layer: the wood fibres are horizontal. 


\subsection{Characterization of the materials}

Cement paste: linear autogeneous shrinkage versus time has been determined according to standard testing procedures (NF P 15-433) and Young's modulus has been obtained by ultrasonic method.

Plywood: the water ingress profiles in wood have been imaged, along the Y direction, during the imbibition process, by means of the gammadensimetry method. Gammadensimetry is based on the absorption of gamma-rays emitted by a radioactive source of Cesium $\mathrm{Cs}^{137}$, which follows Lambert's law. The water content $\mathrm{u}$ is given according to: $\mathrm{u}=\mathrm{m}_{\mathrm{w}} / \mathrm{m}_{\text {dry wood }}$ where $\mathrm{m}_{\mathrm{w}}$ is the mass of water inside the porosity of the wood and $\mathrm{m}_{\text {dry wood }}$ is its oven-dry mass (obtained by drying in an oven set at $103^{\circ} \mathrm{C}$ ). Free strains along the $\mathrm{X}$ direction have been determined at different heights with a micrometer palmer which accuracy is about $\pm 10 \mu \mathrm{m}$ (see fig.1a). Optical microscopy OM has been performed to image the wood microstructure at the cellular level. Thin cross-sections have been observed at magnification x100 after having been additionally treated with bleaching water.

Cement paste-Plywood composite: Global strains, above and below the glue interface, are measured with a micrometer palmer (accuracy: $\pm 10 \mu \mathrm{m}$ ). Digital image correlation (DIC) is used to characterize the local strains and the mechanical incompatibilities, at the scale of the interface and of the microstructure heterogeneities [7,8]. A rather standard optical setup is used to record images of the whole sample (plane X Y, field: $60 \times 60 \mathrm{~mm}^{2}$, pixel size: $30 \mu \mathrm{m}$ ). Samples have been marked with black speckle painting. The image recorded at the beginning of the test is considered as the reference image. The analysis of displacement and strain fields by the CMV software [7] provided information about the swelling of plywood and the initiation of damage, as a function of time. Images have been taken every half an hour through an automatic system.

\section{Results}

\section{Wood and cement paste properties}

Microstructure of wood: OM observations showed that the vessels elements and wood fibres are parallel (V layer) or orthogonal (H layer) to the direction Y, in coherence with the fact that the layers are glued together so that adjacent plies have their wood grain at right angles to each other (see fig. $1 b)$.

(a)

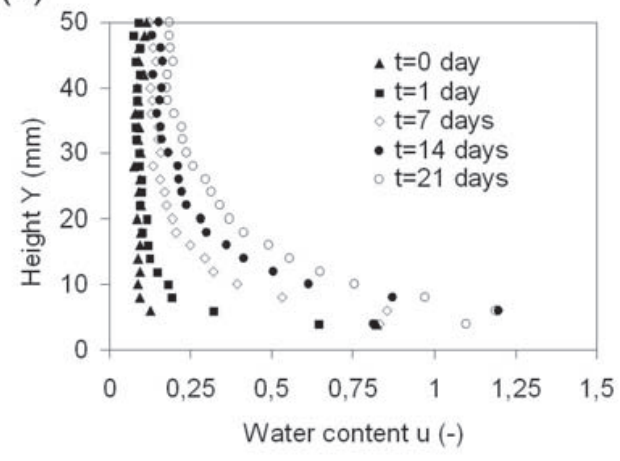

(b)

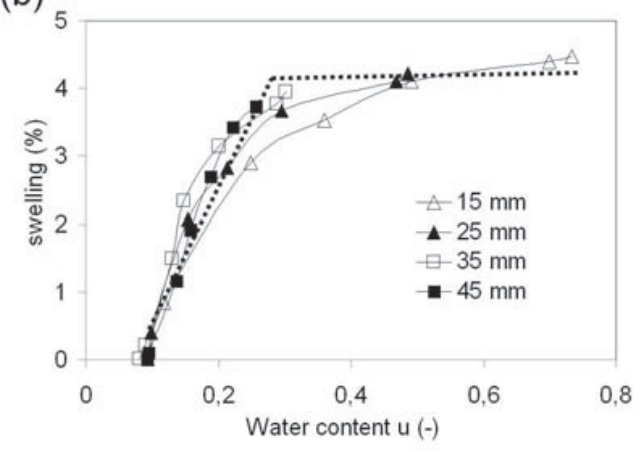

Fig. 2. Imbibition test on wood sample. (a)Water content profile along the $Y$ direction at different times by gammadensimetry method. (b) Swelling of wood versus water content at different heights ( $\mathrm{Y}=45 \mathrm{~mm}$ near the glue interface). 
Water content $u$ and free deformations of wood: Free strains of wood are determined along the direction $\mathrm{X}$ at different heights (average of four values) and are plotted against the water content given by gammadensimetry method. The water content $u$ in wood increases with time (see fig. 2a) because of two different processes: at first capillary migration in the connected vessels, then diffusion in the other wood parts. At the bottom of the specimen, the water content is maximum and equal to about $125 \%$ and near the glue interface varies between about $10 \%$ at $\mathrm{t}=0$ days and $20 \%$ after 21 days of imbibition test. The water content $u$ is quite the same at the heights $Y=35 \mathrm{~mm}$ and $\mathrm{Y}=45 \mathrm{~mm}$. The free deformation measurements at different heights showed that the strain first increases with time and then saturates at about $4.6 \%$ in coherence with the radial strain of Okoumé (see fig. $2 \mathrm{~b}$ and $3 \mathrm{a}$ ). In particular, we showed that the addition of water in wood by imbibition process induces swelling deformation below the fibre saturation point (FSP $\approx 35 \%$, see fig. $2 b$ ).

Properties of cement paste: Free deformation measurements of cement paste after casting at $24 \mathrm{~h}$ showed that the strain decreases with time because of hydration process; it remains almost constant after about 28 days (see fig. 3b). The free strains are equal to about $-210^{-4}$ at 2 days and $-1.210^{-3}$ at 28 days. During hydration process, the Young's modulus increases and remains constant after 28 days as well. It is equal to about $15 \mathrm{GPa}$ at $\mathrm{t}=2$ days and $22 \mathrm{GPa}$ at $\mathrm{t}=28$ days. In the first case (fresh cement paste glued on plywood), the mechanical properties of the cement paste evolve during the imbibition process. In the second case (old cement paste glued on plywood), the properties of the cement paste can be considered as constant, with almost no shrinkage of the glued cement paste due to hydration.

\section{Composite specimen durability}

Global strains: Strains above and below the glue interface have been measured versus time and compared to the free strains (see fig. 3a, 3b). The time to cracking corresponding to the first "visible" crack (with width equal to about $0.1 \mathrm{~mm}$ ) has been determined and the crack path on the outer surface has been observed too (see fig. $4 \mathrm{a}, 4 \mathrm{~b}$ ).

(a)

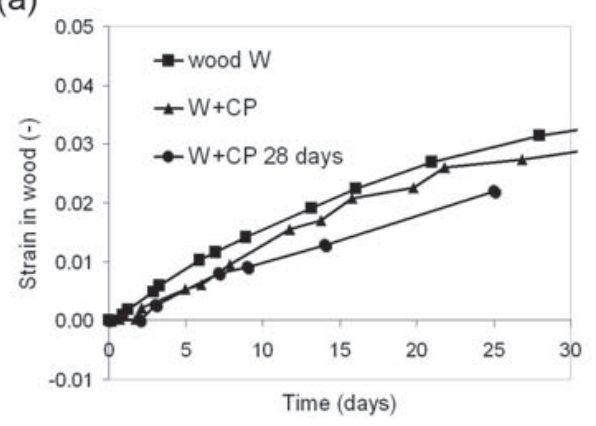

(b)

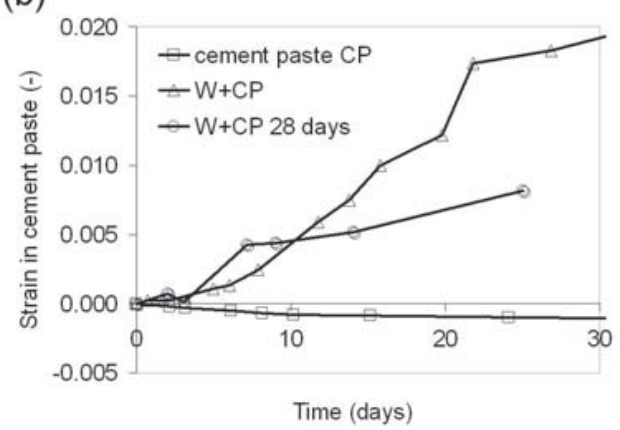

Fig. 3. Free and restrained strains (a) in the wood W and (b) in the cement paste CP. Restrained strains are measured (a) about $5 \mathrm{~mm}$ below the glue interface and (b) above the glue interface.

The strains in wood, below the glue interface, are always inferior to the free strains of wood for the two cases $(\mathrm{W}+\mathrm{CP}$ and $\mathrm{W}+\mathrm{CP} 28$ days). Furthermore, wood swelling is very limited for up to about 2 days as a consequence of restrained deformation due to epoxy glue. The increase of deformation after 2 days may be explained by the fact that the cement paste is damaged (see fig. $4 \mathrm{a}$, 4b). Indeed, deformations at the glue interface are no longer restrained when cracking is observed in the cement paste (after about 4 days). These results are confirmed by deformation measurements in cement paste, above the glue interface. Overall strains in cement paste phase are the same order of magnitude than the strains in wood during the first 2 days. After 2 days, the measured deformation 
increases with time and the measurements essentially quantify the crack openings. Cracking is induced at the glue interface and propagates through the cement paste. Crack opening is larger in the case $\mathrm{W}+\mathrm{CP}$ (fresh cement paste glued to plywood) in coherence with the lower resistance of fresh cement paste.
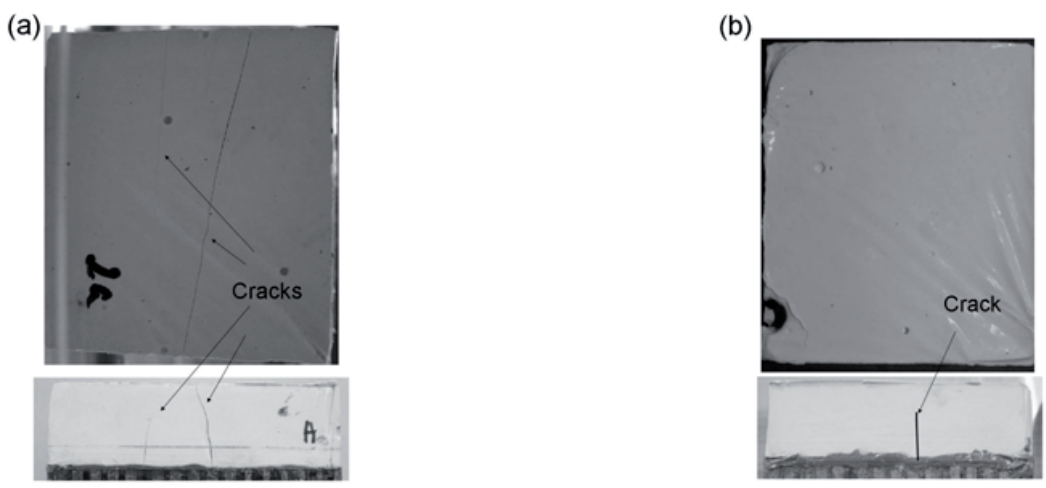

Fig. 5. Cracking pattern at $\mathrm{t}=8$ days (lateral and upper views).

(a) Fresh cement paste glued on plywood $(\mathrm{W}+\mathrm{CP})$. (b) Old cement paste glued on plywood (W+CP 28 days). In the two cases, "visible" cracking is generated at the glue interface at $t=4$ days.

Local strains: Local strains in the glued assembly with fresh cement paste (case $\mathrm{W}+\mathrm{CP}$ ) have been determined with the DIC technique. This analysis allows showing that the response of imbibition process is heterogeneous, as seen in fig. 5a, 5b giving strain maps, relative to a local gage length of about 60 pixels, i.e. about $2 \mathrm{~mm}$. On these maps, the local deformations are represented by little crosses oriented along the principal axes of deformation and with the longer branch along the direction with the higher deformation.

(a)

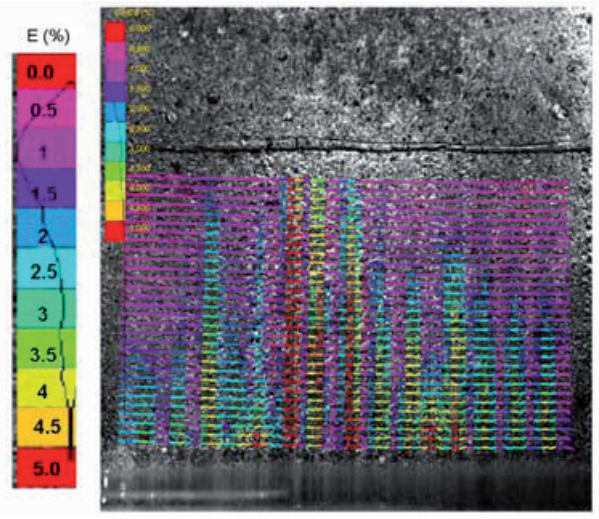

(b)

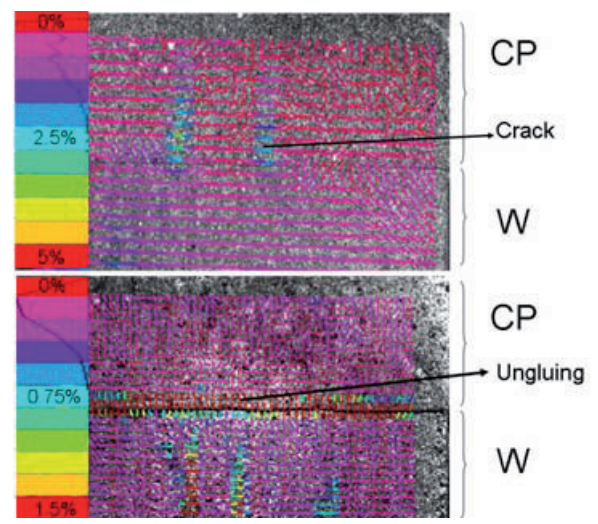

Fig. 5. Colour map of the second invariant of strain field, symbols are oriented along the principal axes.

(a) Local strains in the wood material after 5 days.

(b) Local strains at the glue interface at about 1 day. Case 1: appearance of cracking at the glue interface (in this case the pixel size is $60 \mu \mathrm{m})$. Case 2: Ungluing of the cement paste due to altered glue.

At first, it is shown that the deformation in the wood phase is strongly heterogeneous because of the structure of the plywood. Two levels of deformation can be determined related to the microstructure of the layers of Okoumé. The strain is higher in the layers where the wood fibres are vertical than in the layers where the wood fibres are horizontal. Below the glue interface, the local 
strains are lower in coherence with lower water content $u$ as shown in Fig. 2a. The DIC method shows that there is an effect of the restrained deformations at the glue interface on the strain fields. The restrained deformations at the glue interface induce a bending of the cement paste due to differential deformation between the glue interface and the free surface, as shown by the directions of the eigenstrains. Two cases have been studied. The first case is in coherence with the global deformation measurements and the visual observations. The bending of the cement paste induces a localization of strains at the glue interface at $\mathrm{t}=2$ days leading to cracking. This result is consistent with the measured global deformation in cement paste (see Fig. 3b) and the appearance of cracking at $\mathrm{t}=4$ days. The second case is quite different because the glue was altered. No cracking in cement paste has been observed, but the bending of the cement paste leads to an ungluing, certainly because of weaker adhesion properties.

\section{Conclusions}

Accelerated degradation tests have been carried out for wood-concrete composite: we showed that the imbibition test allows us to determine the efficiency of the glue when the composite samples are subjected to variable hygrometric conditions. Furthermore, digital image correlation has been shown to be an efficient tool for the analysis of the damage mechanisms due to the glue interface.

This work has been complemented by tests with mortars glued on plywood. We showed that the mechanical behaviour is the same whatever the cementitious materials (cement paste or mortar, with or without shrinkage). The relevant parameters are the water content and the elastic properties of wood. These experimental results have been confirmed using an analytical model taking into account the free deformations and the mechanical properties of the wood and of the cementitious material.

Further research is needed to examine durability of glued composites composed of wood and ultra-high-performance concrete under moisture-drying cycles. The durability of these composites will be studied in relation with the anisotropy of wood and with the bonding properties determined by means of push out tests.

\section{References}

1. J.M. Tanis, R. Delfino, R. Le Roy, J.F. Caron, G. Foret, H.S. Pham, M. Cardin, S. Bouteille, J. Resplendino, European project available at http://nr2c.fehrl.org/?m=23\&id_directory=948 (2008)

2. W. Belhack, Optimisation environnementale et structurelle des ponts mixtes en bois, thèse LCPC 2008-2011.

3. J. Custodio, J. Broughton, H. Cruz, A review of factors influencing the durability of structural bonded timber joints, International journal of Adhesion \& Adhesives 29 173-185 (2009)

4. H. Sakagami, J. Matsumura, K. Oda, In situ visualization of hardwood microcracks occurring during drying, Journal of Wood Science, 55 (5), 323-328 (2009).

5. C.-L. Hwang, J.F. Young, Drying shrinkage of portland cement pastes I. Microcracking during drying, Cement and Concrete Research 14 (4) 585-594 (1984).

6. Bisschop J, Drying shrinkage microcraking in cement-based materials, Materials and Structures 2002; 35:453-461

7. M. Bornert, F. Vales, H. Gharbi and D. Nguyen Minh, Multiscale Full-Field Stain Measurements for Micromechanical Investigations of the hydromechanical Behaviour of Clayey Rocks, Strain, 46, 33-46 (2010)

8. Q.T. Nguyen, S. Caré, A. Millard, Y. Berthaud, Analyse de la fissuration du béton armé en corrosion accélérée, C. R. Mecanique 335, 99-104 (2007). 